\title{
Independent forest stewardship auditing ${ }^{1}$
}

\author{
by Rod W. Beaumont, R.P.F. ${ }^{2}$
}

\begin{abstract}
Weldwood of Canada Limited considers independent auditing of forest stewardship and practices to be an essential component of Sustainable Forest Management (SFM). The commitment to continuous improvement implied by SFM requires a management openness and transparency that is best served through the credibility of independent assessment.
\end{abstract}

Key words: environmental auditing, forest sustainability
Weldwood du Canada Limitée considère que la vérification indépendante de l'intendance et des pratiques forestières constituent une composante essentielle de l'aménagement durable des forêts (ADF). L'engagement envers une amélioration continue telle que compris dans l'ADF nécessite une gestion ouverte et transparente qui ne peut être mieux servie que par l'entremise de la crédibilité associée à une évaluation indépendante.

Mots clés: vérification environnementale, durabilité forestière

\section{Introduction}

Auditing or assessment of forest practices and forest management has become a standard element in many forest companies' management structure in the past few years, and that is certainly the case with Weldwood of Canada Ltd. Since beginning our internal forest stewardship reviews in 1992, we have become one of the first companies in Canada to establish a completely independent, third-party audit system to monitor forest practices and forest stewardship.

This independent auditing function is a central element in our company's strong support of national and international certification programs for sustainable forest management.

This paper focusses not on the mechanics of independent stewardship auditing, the "how-to", but rather on the "why", the reasons, the benefits and the necessity of independent auditing to the future of our business in sustainable forest management.

\section{Growing to 1996}

First a brief background on the evolution of our stewardship auditing. In 1992, a team of Weldwood foresters developed and tested an internal woods audit program and protocols. During 1993 all operations underwent an internal audit conducted entirely by staff teams, each audit being led by a divisional Woods Manager, supported by silviculture, harvesting and planning specialists.

In 1994 all divisions were again audited, most using the internal process. Audit protocols were revised to focus more closely on weaknesses or high risk areas of management and practices identified in 1993, and on monitoring of action plans resulting from the previous audits. Some of the audit teams included independent consultants, and staff from other forest companies to bring outsiders perspectives to the reviews. Two of our divisions were audited independently, by two different consultants, using protocols developed by those consultants, with independent specialists providing the technical expertise.

\footnotetext{
${ }^{1}$ Paper presented at the 1996 Annual Meeting of the Woodlands Section, CPPA, 26 March 1996.

${ }^{2}$ Chief Forester, Weldwood of Canada Limited, P.O. Box 2179, Vancouver, British Columbia, Canada V6B 3V8
}

In 1995 Weldwood decided to use one independent auditing firm to conduct stewardship audits on all operations. We selected the firm of Price Waterhouse to do this, based upon their experience in forest management auditing, rigorous application of auditing principles to forest stewardship assessments, and their international credibility.

Wherever possible, the auditors use disciplines and techniques equivalent to those used by financial auditors in examining annual financial statements. The difference with our woodland audits is that Price Waterhouse uses well respected, credible, and independent foresters, engineers and other forestry professionals in the audit process.

This movement from completely internal to completely external auditing was driven primarily by evolution in our objectives and priorities for the stewardship audit program.

In our 1995 program we included observers from other Weldwood divisions, other forest companies, and the general public to maintain the transfer of knowledge between operations. The audits therefore serve an educational role as well, helping the divisions work together toward a common goal of excellence in forest stewardship.

In 1995 we conducted seven Sustainable Forest Management (SFM) audits using draft Canadian Standards Association (CSA) protocols in three provinces across Canada, on four different forms of Crown tenure. We believe this was the largest application of the draft CSA document prior to the CSA's own six pilot audits across the country in 1996.

\section{Evolving Objectives}

Our initial objectives focussed largely on forest management compliance, with company stewardship and environmental policies, with regulatory and licence requirements and with voluntary Codes of Practice to which we are signatory. The internal auditing function served these purposes well, confirming and strengthening our Woodland's management and staff confidence in our own management ability and stewardship performance. Do not be mistaken; our audits found weaknesses as well as strengths, but constructive improvement opportunities cannot be considered failures.

As confidence in the "how-to" compliance issues grew, attention turned to the future "why" of forest auditing. Our 
objectives moved toward continuous improvement, sharing and communication of superior management practices, and proactivity in leading change in forest stewardship.

\section{Sustainable Forest Management}

These objectives epitomize Sustainable Forest Management. Our focus has shifted from the narrow near-term regulatory compliance to the broader Sustainable Forest Management horizon.

Sustainable Forest Management is a recognition of maturing values articulated by the public, voiced through governments, consumers, professionals and the citizen landlords of our public forests. Measuring and improving SFM as an objective responds directly and proactively to the changing values embodied, rather than waiting until those values are translated into regulation, at which time measurement focusses on compliance.

This is where we have raised the sights of our independent forest stewardship audits.

\section{Where Next?}

As our independent auditing program continues in 1996, several opportunities for increased effectiveness in meeting our objectives will be incorporated to increase the communication and sharing of superior management practices.

Observers, both internal and non-company, continue to be included in the program. Community and stakeholder advisors, employees, customers and government agents can not only share learnings, but also contribute to the assessment of both current and future management practices and goals.

As our woods auditing program has developed, we have attempted several communication vehicles to share learnings and good management practices, both within the company and externally. As well as written articles, we have recently produced a video describing the purpose and mechanisms of our independent woodlands auditing program. Auditing is a key component of Weldwood's total forest stewardship commitment, and is communicated in all reporting functions, annual reports, stewardship brochures, and environmental progress reports.
Audits in 1996 will be more individually tailored to each operating division to reflect local priorities and previous audit results, recommendations and action plans. Some audits will focus more heavily on one or two management phases or actions (ie. road construction and maintenance, planning administration, record keeping). The audits of other divisions will continue to have a broad scope that encompasses the range of Forest Management Activities.

In our 1995 program, we included an audit of the draft CSA SFM specifications in each divisional stewardship audit. This gave us a good assessment of where each operation stood relative to the CSA's SFM in the three provinces in which we operate. The CSA documents have continued to evolve during the last year, but we now have a solid foundation on which to build. As the CSA documents near completion, we can begin to put the systems in place to meet the CSA specifications, leading up to a registration audit.

In addition to our regular audit protocols, we will be conducting a Forest Care Certification audit in 1996 at our Hinton Division, under the auspices of the Alberta Forest Products Association.

\section{Summary}

Commitment to SFM encourages a long-term, continuous improvement management attitude, but still requires milestones. Specific measurable standards and targets are necessary to guide actions, monitor performance through time and modify goals as values shift in future.

We believe that independent, arms-length forest management auditing is an essential demonstration that our company recognizes and responds to the societal values underlying Sustainable Forest Management. 